\title{
Las regiones en México: nuevas lecturas e interpretaciones
}

\author{
Odile Hoffmann
}

JAIME PRECIADO CORONA, HÉLÈNE RIVIÈRE D'ARC, LUIS ALFONSO RAMÍREZ, MARIELLE PEPIN-LEHALLEUR (coords.), 2003

\section{Territorios, actores $y$ poder. Regionalismos emergentes en México}

Universidad de Guadalajara-Universidad de Yucatán, México, 419 pp.

$\mathrm{E}$ ste libro es fruto de una cooperación Francia-México, mediante el programa ECOS: cooperación entre investigadores confirmados y principiantes, tanto mexicanos como franceses; entre instituciones de docencia y de investigación, tanto en Francia como en México ; entre pensamientos y técnicas de investigación que siguen teniendo sus especificidades y sus limitaciones. Gracias a esta configuración se ha producido una obra fecunda, coordinada por Jaime Preciado, Hé- lène Rivière d'Arc, Luis Alfonso Ramírez y Marielle Pepin-Lehalleur, donde se confrontan diversas tradiciones teóricas respecto al regionalismo.

Los coordinadores destacan en la introducción cuatro enfoques, más que disciplinas, que históricamente han guiado la reflexión acerca de los regionalismos: región y regionalismo con énfasis cultural; el aporte del enfoque político; las nuevas tendencias de la geografía política y la perspectiva de la economía regional. En el

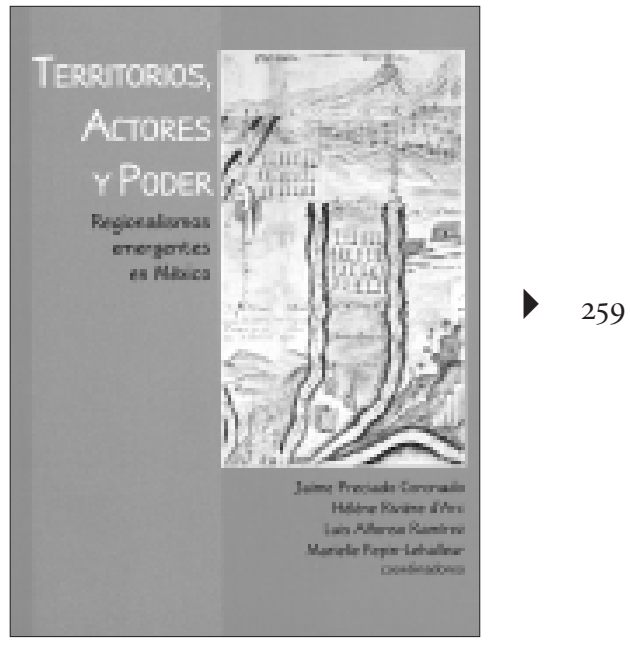

desarrollo de cada uno de estos acercamientos exponen los planteamientos "clásicos" sobre región y regionalismo, los cuales son críticamente revisados y ampliados a la luz de corrientes más recientes. En esto el libro es, de por sí, un aporte teórico-metodológico de gran valor para estudiantes e investigadores.

Región, regionalismo, regionalizaODILE HOFFMANN: CIESAS-IRD. ción, recomposición regional, si bien es cierto que en primera instancia se 
comprende qué es lo que se trata - entender los cambios en y desde las regiones-, tanto el título como la estructura, y por ende los contenidos de los artículos, provocan la reflexión y escapan de una simple compilación de "estudios de casos".

Una pregunta teórica recorre todo el libro: ¿se pueden explicar los procesos regionales por una serie de estrategias desarrolladas por los actores de distintos niveles, o existen fuerzas históricamente constituidas que conllevan dinámicas que no siempre se pueden asociar a tal o cual actor o interés? En otros términos, existe una "vida de las regiones", cuya inercia y lógica no forzosa ni fácilmente dan cuenta de fuerzas económicas, culturales o políticas de hoy? O más aún: ¿existen "regiones" más allá de las representaciones que se tiene de ellas en un momento dado? Esta interrogación implica una exigencia metodológica que consiste en combinar acercamientos en plazos distintos: en el tiempo largo de la construcción de las representaciones del espacio regional y en el tiempo corto de la coyuntura política en la que se puede observar dinámicas regionales, como por ejemplo, la transición democrática, el debilitamiento de las formas corporatistas y la emergencia de nuevos regionalismos, por sólo mencionar algunos de los procesos en curso. Sólo contrastando —y si es posible relacionándolas_ las dos dimensiones temporales se puede evaluar con cierto grado de seguridad los impactos respectivos de los procesos y ver cómo, en su articulación, contribuyen a "producir una región". De la misma manera, se necesita combinar distintos niveles espaciales para evitar cualquier simplificación. De los "territorios de la solidaridad", que corresponden muchas veces con los territorios municipales, hasta las vastas regiones que pueden incluir varios estados, el espacio funge como argumento y discurso performativo en los esfuerzos de sus habitantes para darse a conocer y a reconocer, base de cualquier regionalismo. Finalmente, para ser congruente con el objeto de estudio (procesos más que situaciones acabadas), los investigadores tuvieron que acercarse a las regiones a partir de actores diversificados, desde las élites locales, las capas populares o los intervinientes en el juego político, que no siempre coincidan con uno u otro nivel de acción o de discurso. En esto, el libro logra poner en práctica lo que se enseña en los cursos pero que rara vez se logra : articular tiempos, espacios y actores alrededor de una temática.

La estructura de la obra privilegia decididamente la entrada política, al estudiar la posible emergencia de nuevos regionalismos desde la sociedad civil (primera parte), desde las élites y algunos actores privilegiados (segunda parte), y finalemente como construcción política compleja (tercera parte). Como lo señalan los coordinadores en la introducción, "el regionalismo es una construcción política” (p. 11-12): aunque nació en la tradición académica por sus dimensiones económicas o culturales, el regionalismo no se debe a configuraciones "culturales" preexistentes (el regionalismo corzo o bretón en Francia, o yucateco aquí) sino a interpretaciones sociales y políticas de dichas configuraciones. Con esta opción se deslindan de una vez de cualquier tentación esencialista o culturalista que muchas veces entinta los estudios de los regionalismos, y proponen nuevas vías de entenderlos.

En su trabajo sobre descentralización y regionalismo, Hélène Rivière d'Arc habla de regionalismos y no de regiones. Pretende auscultar procesos, estrategias, interacciones con actores, sean élites, habitantes o migrantes. Esto le permite comparar la región norte del país, empresarial, con las regiones indígenas del sur, viendo cómo la descentralización actúa como potente diferenciador o aglutinador de reivindicaciones "regionalistas", aunque con expresiones diversas.

El esfuerzo conceptual y metodológico de Jaime Preciado nos adentra en las ambigüedades y contradicciones de los conceptos de región y regionalismo, proponiendo para Jalisco una sugerente tipología que podría exportarse a otras zonas del país. Sin embargo, no me convence totalmente la distincción entre regionalismo comunitario y contractual. ¿Qué es el comunitario sino un regionalismo contractual históricamente constituido y anclado en un espacio que a partir de entonces se llama "territorio", que goza de cierto consenso y termina por no ser cuestionado? El ejemplo de la región Pacífico de Colombia podría ilustrar este fenómeno: habitada por descendientes de esclavos negros, construida por y en contra del Estado esclavista como refugio, desde los siglos XVIII-XIX, es hoy base de reivindicación por parte de los militantes negros que la reivindican como su "territorio región". No se puede hablar 


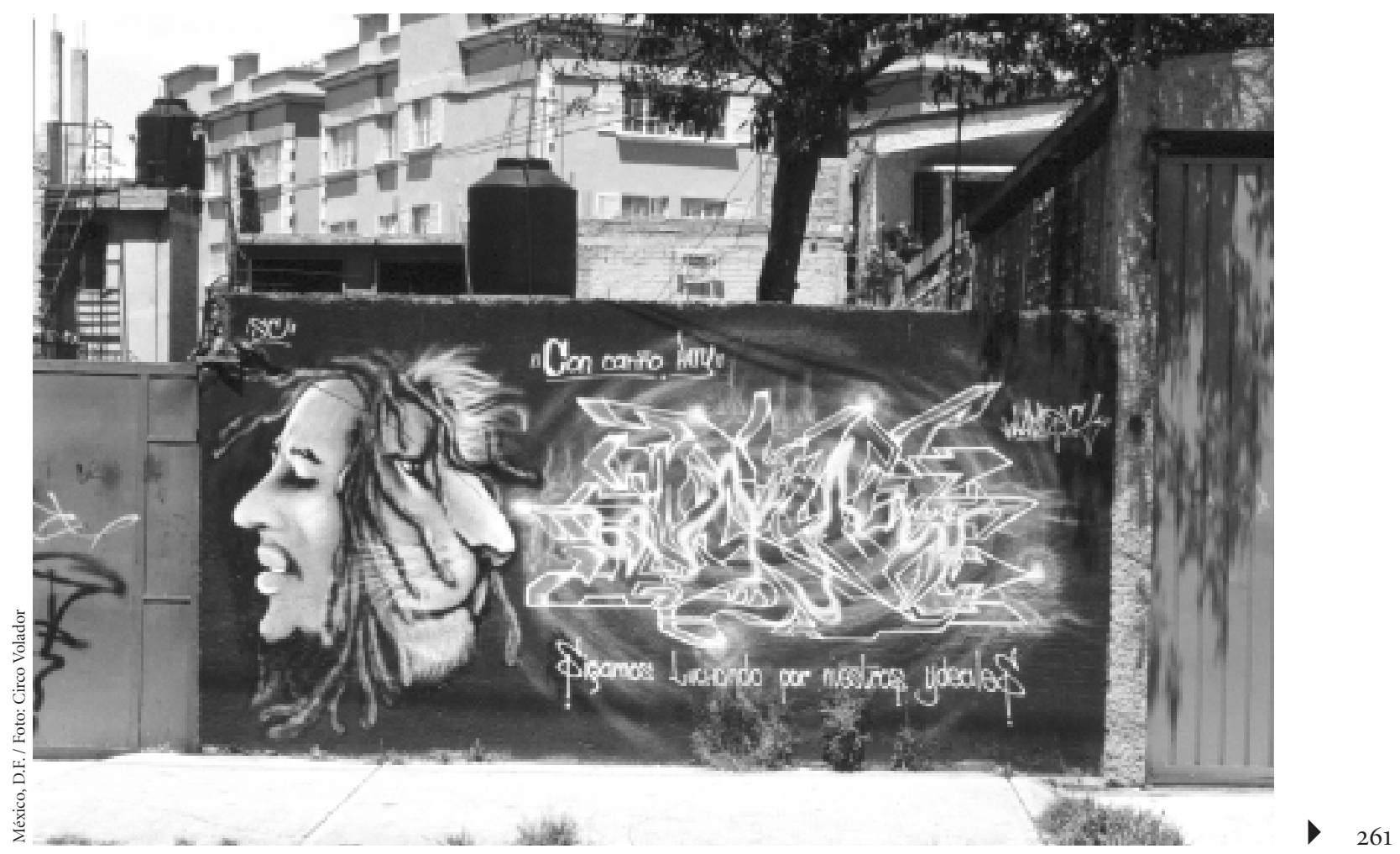

de "regionalismo comunitario" aquí, sino de un espacio de lucha, de un espacio de relaciones "contractuales" aunque desiguales, hoy re-interpretado en términos culturales.

Precisamente en esta dimensión cultural, Marielle Pepin-Lehalleur nos presenta un estudio muy fino que muestra como ésta es fruto a la vez que motor de solidaridades y antagonismos que se entretejen para "formar región” en la costa chica de OaxacaGuerrero. Ninguna reificación de la cultura aquí, sino un análisis anclado en tiempos y en espacios que nos hablan de unas prácticas de acción política, de cultura y de memoria que propician un "regionalismo popular" muy sui generis, construido entre poblaciones indígenas, negras y mestizas.
En varias de las aportaciones se privilegia el acceso a los estudios por medio de la economía, reconociendo en los actores económicos un papel de reordenamiento regional que se vuelve eminentemente político. Así vemos, en Yucatán, cómo la desterritorialización anunciada con las maquiladoras no se da (Christian Azais), pero reconstruye un espacio regional que el autor prefiere conceptualizar como territorio, subrayando así el papel constructor de los actores. A su vez, Nathalie Gravel muestra cómo la memoria del henequén pierde pertinencia en el nuevo contexto económico y cómo se busca una alternativa en las representaciones que se construyen alrededor de las maquiladoras. Para seguir con Yucatán, Luis Alfonso Ramírez analiza, a lo lar- go del siglo XX y un poco antes, la forma en que la élite regional se adapta y se transforma, hasta conformar una "élite integrada" a pesar de su diversificación (regional, nacional, transnacional). Por su lado, como lo muestra Othón Baños, la apertura del regimen político nacional cuestiona un sistema regional que se ha construido alrededor de un caudillismo entregado, con un "hombre fuerte" y un autoritarismo regional a la sombra del PRI centralizador. Otro reto fuerte al que se enfrenta el regionalismo yucateco podría ser el de la diversificación de sus pobladores, con procesos agudos de inmigración (Sebastien Gaultier) ¿Cómo se redibujan los ámbitos de negociación y de vida con la llegada de nueva gente, de nuevas actividades $y$ 


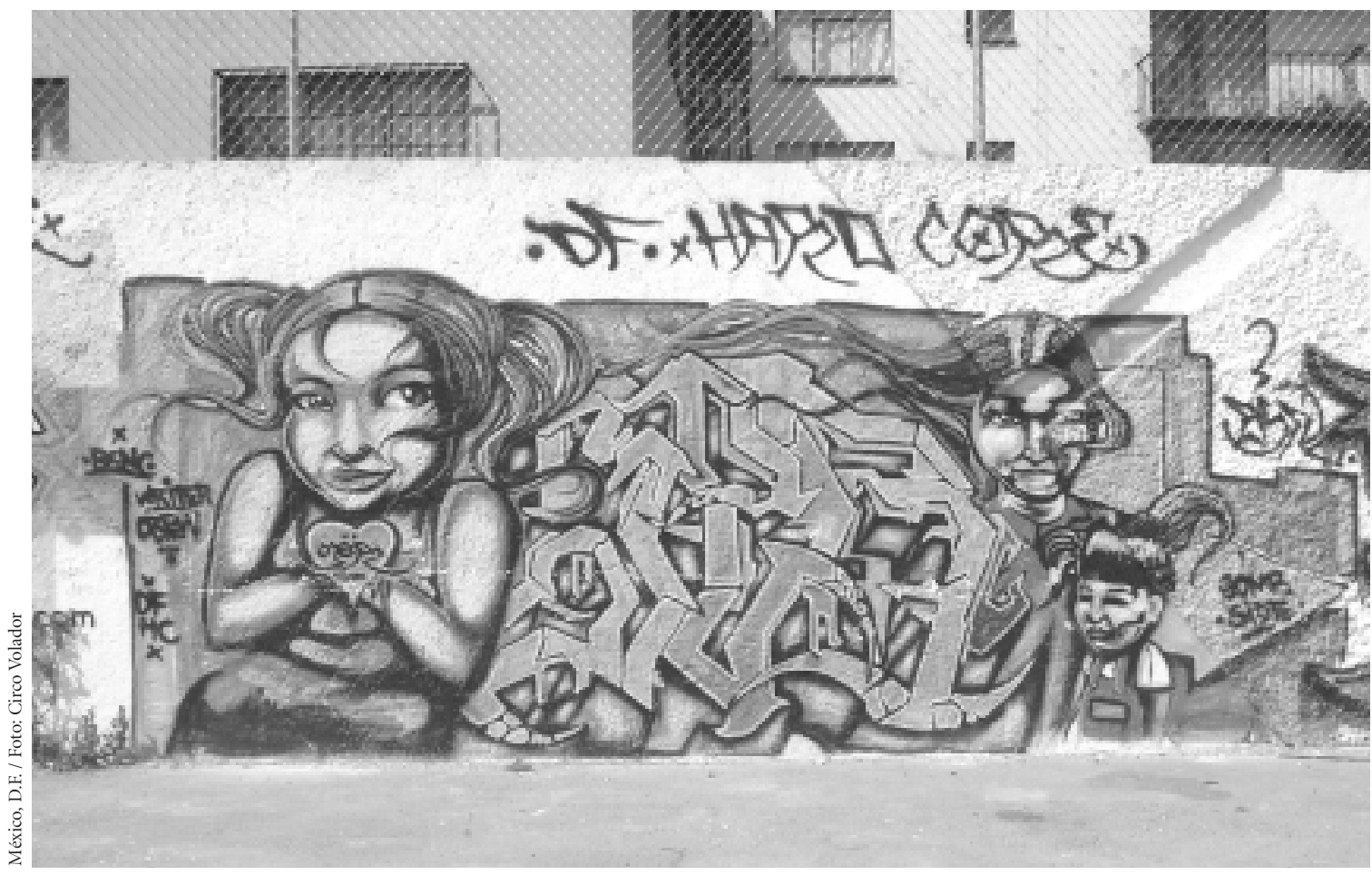

de nuevos discuros (ambientalismo, conservacionismo)? Estos capítulos aportan una visión compleja y matizada del regionalismo en Yucatán, en especial de su capacidad de reconversión y de adaptación a la globalización y a los cambios políticos y económicos nacionales de los cuales se nutre. No es un regionalismo "comunitario" ni "cultural", sino un dispositivo activado por actores económicos, políticos o culturales insertos en la globalidad de su región, de su nación y de su mundo en general.

El caso de Jalisco no es menos complejo, como lo menciona de entrada Enrique Valencia al apuntar las transformaciones radicales de los sistemas de producción y cómo éstas afectan a su vez la producción del espacio en los últimos 15 años. Para referirse a este periodo habla incluso de un "regionalismo de catástrofe" (1985-1995) y analiza cómo, después, se reconstruye un posible regionalismo "contractual" -y por ahora esencialmente discursivo- como alternativa. En esta reconstrucción intervienen el nivel local (identidad jaliscience), el nacional (bajo la figura del centro) y el internacional (con la de la globalización), así como los ámbitos empresarial y político, con la alternancia y el gobierno del PAN. Es un buen ejemplo de cómo el regionalismo se construye con flujos y contraflujos inducidos por las realidades económicas y políticas, pero no mecánicamente sino siempre reinterpretándolas.

El papel central del discurso es igualmente subrayado por Jorge Alonso e Isabel Blanco cuando analizan la participación de la sociedad civil en Jalisco. Muestran cómo la alternancia significó al principio una buena acogida del PAN hacia la sociedad civil, que sin embargo no se traduce (¿todavía?) en prácticas novedosas. Se mencionan avances que se mantienen en el ámbito simbólico, pero con ciertos efectos políticos pues renovaron las relaciones ONG-partidos-gobierno.

Muestra bien cómo el límite discursopráctica, o simbólico-político, puede variar, desvanecerse 0 , al contrario, erigirse barreras. Y también cuánto "la sociedad civil", en su diversidad de expresión, constituye hoy un actor múltiple e incontornable de la vida política regional.

Con menos esfuerzos explícitos de construcción discursiva, incluso quizás sin ellos, otros actores privilegiados 
participan en la vitalización de regiones: pienso en las "regiones mafiosas" analizadas por Jean Rivelois, en las que, según el autor, se está elaborando "un nuevo contrato socioterritorial, basado en interacciones específicas entre el centro y los márgenes de los sistemas políticos". Con un "cierto reconocimiento de la ilegalidad", el centro integra a los márgenes y asegura así su permanencia. Quizás donde yo mantenga ciertas dudas es en la asimilación que hace el autor entre distintas modalidades de regionalismo, por ejemplo, entre las dinámicas regionalistas mafiosas y las étnicas. Me parece que las segundas, amparadas en su afán de democratización y ciudadanía, difícilmente pueden equipararse con las primeras cuya finalidad es la sola garantía de su libertad de acción.

Finalmente, un grupo de textos valoriza los ámbitos locales en las construcciones regionales. Me parece fascinante la persistencia del municipio como nivel pertinente de acción y de representación política, "irrigado" y reactivado por redes de tipo corporativista tradicional (María del Carmen Cebada) y político partidista (Jorge Ceja). A pesar de los fenómenos de globalización, de democratización, de migración, la vida local sigue siendo aquélla donde se organizan los grupos de poder con injerencia directa en los pobladores, es decir, con más poder de interacción y de representación. Sólo que no se trata de grupos restringidos al ámbito local, sino de partícipes de redes que pueden abarcar espacios mucho más extensos, tanto en sus acciones como en sus legitimaciones. Un ejemplo paradigmático podría ser el de Puerto Vallarta, nacido por el turismo internacional y que busca en la identidad local un "valor compartido". Sin embargo, en este caso, Salvador Gómez nos habla más bien de identidades múltiples, o de múltiples espacios de pertenencia, en un contexto de introducción del nuevo sistema de recursos y de valores (el turismo) que organiza la sociedad local entre "dominantes" y "dominados" del turismo, en una nueva jerarquía ideológica que a su vez reordena la cultura local.

Como trato de indicarlo, cada capítulo aporta su piedra al edificio, con fuerte sustento empírico a la vez que un marco teórico que permite tender puentes hacia los demás, lo que hace del libro una verdadero estudio, coherente y rico en su diversidad. Del conjunto de capítulos se desprende que, a pesar de las tendencias a subvertirlo o rebasarlo (transnacionalismo, cosmopolitismo, globalización), el Estado central no está muerto y sigue organi- zando las regiones y los regionalismos. Las reivindicaciones, aunque sean de corte cultural o económico, se expresan en la modalidad política de la relación con el Estado. En este sentido, los regionalismos están inmersos en la modernidad y, hasta donde se estudió aquí, no entran en las lógicas posmodernas de multi-pertenencia social o identitaria. A este respeto, sin entrar a debatir acerca de si "la región ha muerto" o no, se evidencia el hecho de que las regiones se siguen buscando, redefiniendo, reactualizando bajo formas nuevas de discursos y de prácticas que a veces se explicitan como "regionalistas" y a veces no. Lo que quizás desapareció es la pretensión unificadora y planificadora de "la región" como concepto integrador, pero tal vez solamente hasta que llegue otra ola de descentralización que las relegitime...

En conclusión, tenemos aquí un libro que renova y aporta al conocimiento de los regionalismos contemporáneos, pero sobre todo a la reflexión acerca de la gran vitalidad y diversidad política que conoce el país desde la apertura del sistema político. Un libro de referencia, sólido y argumentado, que cada uno podrá disfrutar y utilizar para sus propios fines e intereses. 